\title{
Determinants of polycyclic aromatic hydrocarbons in smoked bushmeat
}

\author{
Iddrisu Wahab Abdul ${ }^{1,}$, , Martin Owusu Amoamah ${ }^{1}$, Abu Abdallah ${ }^{2}$ \\ ${ }^{1}$ Department of Mathematics and Statistics Accra Polytechnic, Accra, Ghana \\ ${ }^{2}$ Department of Chemistry, KNUST, Kumasi, Ghana
}

\section{Email address:}

perfectwahab@yahoo.com (I. W. Abdul)

\section{To cite this article:}

Iddrisu Wahab Abdul, Martin Amoamah, Abu Abdallah. Determinants of Polycyclic Aromatic Hydrocarbons in Smoked Bushmeat. International Journal of Nutrition and Food Sciences. Vol. 3, No. 1, 2014, pp. 1-6. doi: 10.11648/j.ijnfs.20140301.11

\begin{abstract}
The Ashanti Region located at the central part of Ghana is harboring about $60 \%$ of the nation's forest reserves. This undoubtedly makes the region and Ghana one of the major consumers of bush meat since a larger percentage of the wild species reside in these forest reserves. Unfortunately however the obsolete technologies used in processing the meat are very likely to induce PAHs in the meat. Processed meat (bushmeat) using smoke from burnt car tyres is raising serious concern because of the adverse effects it may have on consumers. This paper therefore investigates to assess the levels of PAH in smoked bushmeat and determine among the substances/methods used in singeing off the hair of animals in flames, the substance/method that produces the least PAHs. One-way analysis of variance (ANOVA) for $\alpha=0.05$ was used to show the variations in PAH values according to the substance/method used in singeing off the hair of animals in flames. The results reveal that, when bushmeat is smoked using Gas it produces smaller PAH values compared with bushmeat smoked using wood mixed with spent oil, plastics mixed with refuse, and discarded car tyres.
\end{abstract}

Keywords: Smoked Bushmeat, Polycyclic Aromatic Hydrocarbons (PAHs), ANOVA

\section{Introduction}

Polycyclic aromatic hydrocarbons (PAHs) are a group of environmental contaminants that emanate from incomplete combustion of fuel or high temperature pyrolysis of fats and oils. It is well known that PAHs occur in curing smoke and that they accumulate on meat products being smoked [1]. They have been extensively researched into because of their carcinogenicity and mutagenicity to animals [5]. In 2001, PAHs ranked 9th on the list of most threatening compounds to human health [6].

\subsection{Chemical Nature and Toxicity of PAHs}

PAHs consist of several hundreds of compounds containing molecules having two or more benzene rings fused together. Some of the PAHs identified are shown in Table 1. Polycyclic aromatic hydrocarbons are environmentally persistent due to their relative chemical stability and resistance to biodegradation. Many reports have shown that exposure of human body to the environment containing PAHs may induce some fatal diseases such as lung and skin cancers [2].
Table 1. Names and chemical structure of some common PAHs

\begin{tabular}{|c|c|c|c|}
\hline Name & Acronym & Structure & $\begin{array}{c}\text { Molecular mass } \\
(\mathrm{AMU})\end{array}$ \\
\hline Acenaphthene & $\mathrm{ACP}$ & & 154 \\
\hline Anthracene & ANT & & 178 \\
\hline Fluoranthene & FLT & & 202 \\
\hline Fluorene & FLR & & 166 \\
\hline Naphthalene & NAP & & 128 \\
\hline Phenanthrene & PHE & & 178 \\
\hline Pyrene & PYR & & 202 \\
\hline
\end{tabular}




\begin{tabular}{lll}
\hline $\begin{array}{c}\text { Name } \\
\text { cene }\end{array}$ & Acronym \\
$\begin{array}{c}\text { Benzanthra } \\
\text { anthene }\end{array}$ & $\mathrm{BaA}$ Structure \\
Benzo[a]pyre \\
ne
\end{tabular}

Due to their carcinogenic potential, PAHs have been studied widely in mammals [7] and concern for human population has stimulated interest in knowledge of their distribution as well as accumulation in the environment and in food items. The carcinogenic potential of the PAHs was first elucidated by Percival Pott of St. Bartholomeo's Hospital in London in 1775 when he noted high incidence of cancer of the scrotum among chimney sweepers who had often climbed up inside chimneys to sweep down the soot. Although he deduced correctly that the soot was responsible for the cancer, it was not possible to determine the compounds responsible for such serious tissue damage at that time [3].

\subsection{Bush Meat in Ghana and Their Possible Health Hazards}

Bushmeat is an important component of household food security and income in West and Central Africa. Bushmeat, the meat of wild animals, is one of the most valuable tropical forest products after timber [4]. It is an important food source, consumed in both rural and urban areas, and can make a significant contribution to the cash income of rural households living in extreme poverty. In Ghana, bushmeat is widely available alongside domestic meat and fish. Whilst consumers prefer the taste of bushmeat, domestic meat and fish are less expensive and are more widely eaten. Bushmeat is eaten throughout the year, but its high price means that it tends to be purchased in only small quantities. Its consumption peaks during festivals and holidays. Bushmeat is mostly sold processed (i.e. dressed and smoked): smoked meat has a longer shelf life, but is nearly twice as expensive. Overall, the monthly volume of bushmeat sold by retailers is $15,859 \mathrm{~kg}$ with a retail value of US\$48,000, subject to seasonal variation. If additional sources of bushmeat are incorporated (from informal sales, gifts, and personal captures), total bushmeat consumption in a Ghanaian city can be estimated at $21,410 \mathrm{~kg}$ per month, or about $0.01 \mathrm{~kg}$ per person per day [8].

An issue that has not been given the needed attention in the Ghanaian market is how bush meat is processed for consumption and its implication on the health of the consuming public. A number of factors related to the smoking process affect the composition of smoke as well as the PAHs uptake in the products, with the combustion temperature being critical [9]. There is very little or no chemical investigation into the use of smoke in the processing of the bushmeat which is a common practice in Ghana.

Smoking is a processing technique in which meat is exposed directly to wood smoke which may be generated by a variety of methods [10]. The presence of PAHs in foods has been investigated by many researchers. Several processing methods, including smoking, grilling and roasting, have been reported to induce formation of PAHs in foods. Of the various types of foods investigated, processed meat products were found to contain high amount of PAHs [11]. Thus, the formation of PAHs during processing of foods poses a potential health hazard to humans.

\subsection{Objectives}

The specific objectives are:

1. To assess the levels of PAH in smoked bushmeat.

2. To determine among the substances/methods used in singeing off the hair of animals in flames, the substance/method that produces the least PAHs

\section{Materials and Methods}

\subsection{Reagents and Chemicals}

All reagents were of analytical grade and the water of Millipore-Q quality. 96.5\% hexane, 99.5\% acetone, 20\% diethylether, $100 \%$ methanol, anhydrous sodiumsulphate, silicagel ( $5 \%$ water content).

\subsection{Equipments and Instruments}

Centrifuge, rotary evaporator, nitrogen gas evaporator isolute SPE PAH HC $1 \mathrm{~g}$ columns, reservoir $6 \mathrm{ml}$, glasswool, Gas-chromatography/mass spectrometer.

\subsection{Sampling}

Commercially smoked bushmeat (about $2.5 \mathrm{~kg}$ ) of twelve different species commonly consumed in Ghana, namely antelope (cephalophus maxwellii), Grass cutter (Thryonomys swinderianus), Bushcow (Syncerus caffer nanus), bushbuck (Tragelaphus sciptus), Rat (cricetomys gambianus), squirrel (protoxerus strangeri), bushpig (potamochoerus porcus), bushrabbit (lepus spp), cockbird, bush guineafowl, bushcat (felis aurata),monitorlizard (varanus niloticus), were purchased from three different market centres from local vendors in Kumasi, Ghana. These vendors use various substances/methods in singeing off the hair of the animals in flames including Gas, Wood mixed with spent engine oil, Plastics mixed with refuse, and discarded car tyres.

Each of the twelve different bushmeat samples were purchased from three different market centres in Kumasi 
including Asafo, Central market, Atwemonom (Kejetia) from commercial local meat vendors. Samples from different vendors were pooled together to obtain representative samples (for A, B, C, D, E, F, G, H,I, J, K, L) for each of twelve types of meat products analysed. Representative smoked bushmeat were deboned, cut into smaller pieces. An aliquot of each of the representative sample so obtained (about $100 \mathrm{~g}$ ) was milled, packed in aluminium foil wraps and stored in the freezer at-20c before analysis.

\subsection{Extraction}

PAH extraction was carried out by applying the method by [10], with some modifications. $1 \mathrm{~g}$ of milled sample were weighed into a test tube and $10 \mathrm{ml}$ of distilled water was added. The mixture was taken through the centrifuge at $3000 \mathrm{rpm}$ (revolutions per minute) for 10 minutes. The supernatant was transferred into a new tube. To the residue was added $10 \mathrm{ml}$ of 1:2 acetone: hexane and shaken for ten minutes. The mixture was taken through the centrifuge at $3000 \mathrm{rpm}$ for 10 minutes. The supernatant obtained was passed through anhydrous sodium sulphate. $30 \mathrm{ml}$ of hexane was added to the residue, mixture shaken and put in ultrasonic for 10minutes and the supernatant obtained was passed through anhydrous sodium sulphate. The sample obtained after passing through anhydrous sodium sulphate was concentrated by rotary evaporator, transferred into a test tube, the flask was washed three times with hexane and hexane was added and shaken well. The mixture was taken through the centrifuge at 2000rpm for five minutes. The supernatant (hexane layer) was transferred into a new tube, the process was repeated and the supernatants are added together and made up to $10 \mathrm{ml}$ with hexane.

Clean-up: The $10 \mathrm{ml}$ supernatant (hexane layer) was concentrated to approximately $1 \mathrm{ml}, 300 \mathrm{uL}$ of methanol was added and SPE column chromatography was performed. Elution of sample carried out with $10 \mathrm{ml}$ of $(1: 4)$ ie $20 \%$ diethylether: $80 \%$ hexane. Eluate was concentrated to $2 \mathrm{ml}$ and transferred into a sample vial and stored in a refrigerator for analysis.

\subsection{Statistical Analysis}

One-way analysis of variance (ANOVA) for $\alpha=0.05$ was used to show the variations in PAH values according to the substance/method used in singeing off the hair of animals in flames. We report all values as means. All statistical calculations and graphs were produced using both SPSS and Ms Excel. Least significant difference (LSD) was used to determine levels of significance between pairs.

\section{Results and Discussion}

\subsection{Levels of Pahs in Smoked Bush Meat}

In this study, 12 samples of different smoked bush meats were analyzed and the concentrations of PAHs were determined.
Figure 1 shows that samples of smoked bush meat contained Naphthalene concentrations. On the basis of obtained results it was found that smoked Antelope contained Naphthalene in concentrations substantially higher $(0.353 \mathrm{ppm})$ in comparison with the other 11 smoked bush meat samples. Followed by smoked Boar $(0.261 \mathrm{ppm})$, smoked Grass cutter (0.251ppm), Bush cat $(0.233 \mathrm{ppm})$, Squirrel (0.232ppm), Cock bird (0.227ppm), Monitor lizard (0.227ppm), Bush cow (0.225ppm), Bush rabbit (0.22ppm), Bush guinea fowl (0.208ppm), Bush buck (0.076ppm), Rat (0.011ppm), respectively.

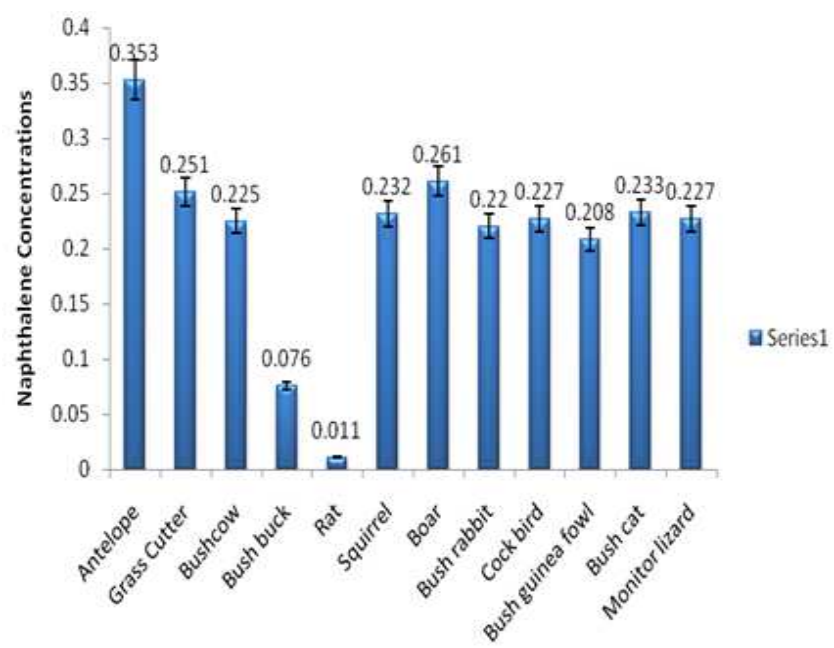

Figure 1. Naphthalene concentrations for the arious bushmeat samples

Figure 2 show that samples of smoked bush meat contained 2-Methylnaphthalene concentrations. On the basis of obtained results it was found that smoked Antelope contained 2-Methylnaphthalene in concentrations substantially higher $(0.399 \mathrm{ppm})$ in comparison with the other 11 smoked bush meat samples. Smoked Rat did not contain 2-Methylnaphthalene (0.00ppm) at all.

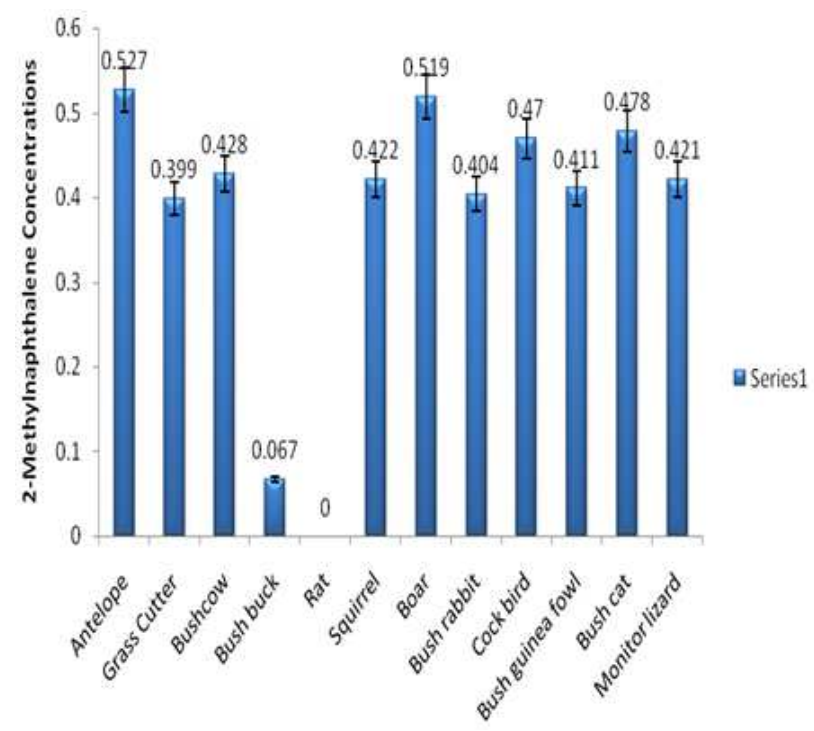

Figure 2. 2-Methylnaphthalene concentrations for the various bush meat samples 
Figure 3 also show that samples of smoked bush meat contained Acenaphthylene concentrations with the exception of smoked Rat. On the basis of obtained results it was found that smoked Antelope contained Acenaphthylene in concentrations substantially higher $(0.114 \mathrm{ppm})$ in comparison with the other 11 smoked bush meat samples.

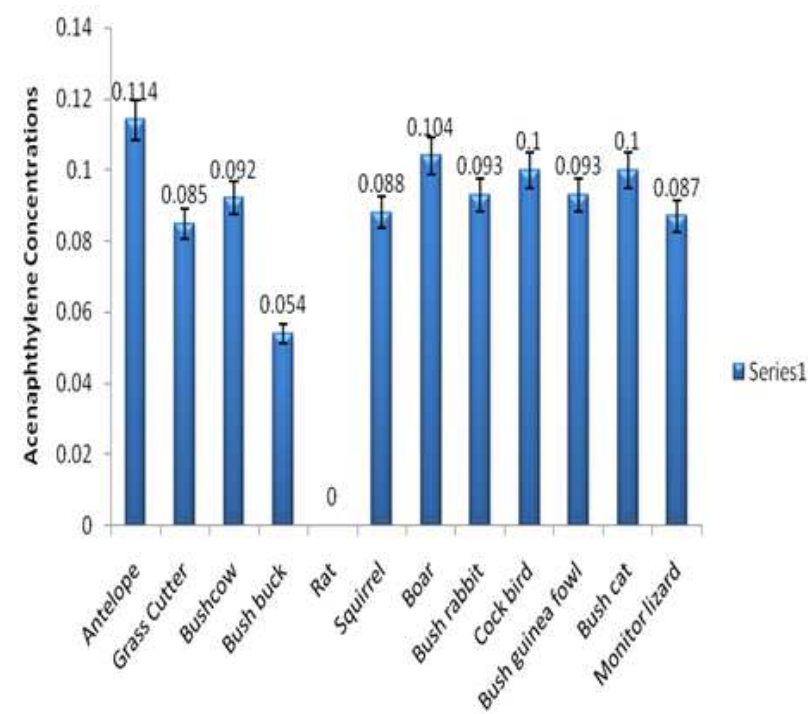

Figure 3. Acenaphthylene concentrations for the various bushmeat samples

Figure 4 show that samples of smoked bush meat contained Acenaphthene concentrations. On the basis of obtained results it was found that smoked Antelope contained Acenaphthene in concentrations substantially higher $(0.515 \mathrm{ppm})$ in comparison with the other 11 smoked bush meat samples. Smoked Rat contained the least Acenaphthene concentration (0.063ppm).

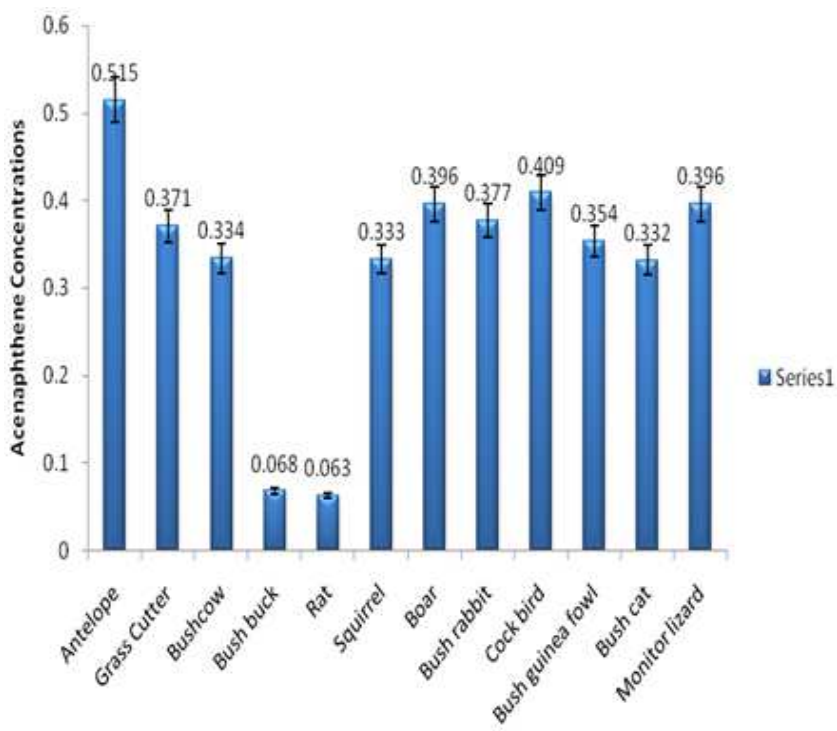

Figure 4. Acenaphthene concentrations for the various bush meat samples

Figure 5 show that samples of smoked bush meat also contained Fluorene concentrations. On the basis of obtained results it was found that smoked Bush Cat contained
Fluorene in concentrations substantially higher $(0.132 \mathrm{ppm})$ in comparison with the other 11 smoked bush meat samples. Smoked Bushcow and Rat did not contain Fluorene at all.

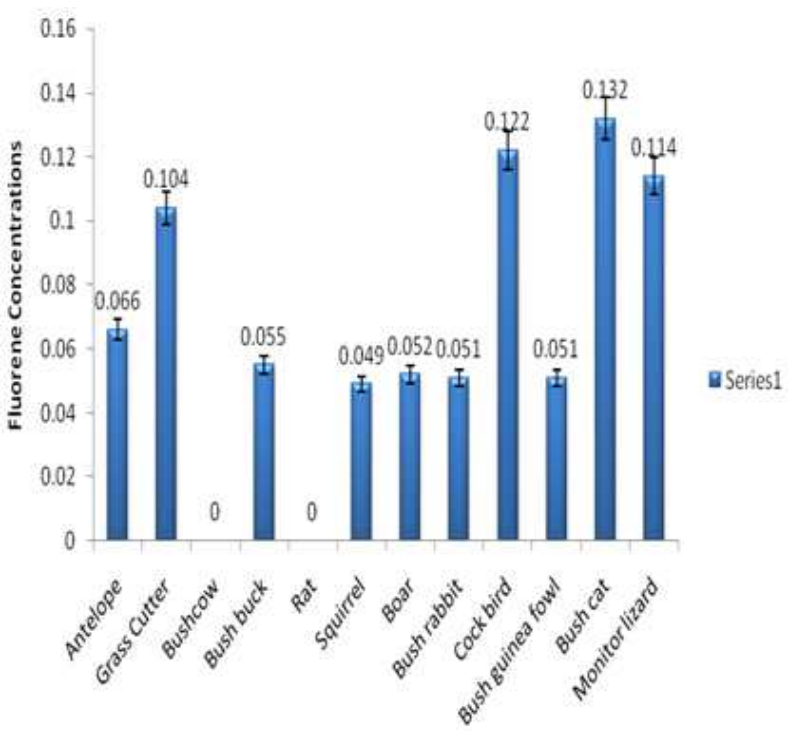

Figure 4. Fluorene concentrations for the various bushmeat samples

Figure 6 show that samples of smoked bush meat also contained Phenanthrene concentrations. On the basis of obtained results it was found that smoked Antelope contained Phenanthrene in concentrations substantially higher $(0.92 \mathrm{ppm})$ in comparison with the other 11 smoked bush meat samples.

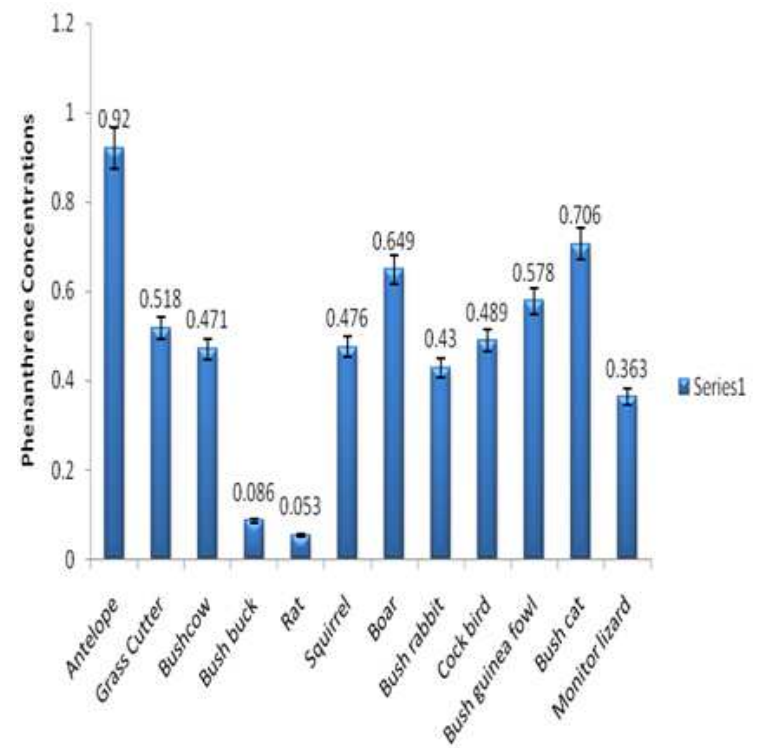

Figure 5. Phenanthrene concentrations for the various bushmeat samples

Figure 7 show that samples of smoked bush meat also contained Anthracene concentrations. On the basis of obtained results it was found that smoked Antelope contained Anthracene in concentrations substantially higher $(0.096 \mathrm{ppm})$ in comparison with the other 11 smoked bush meat samples. 


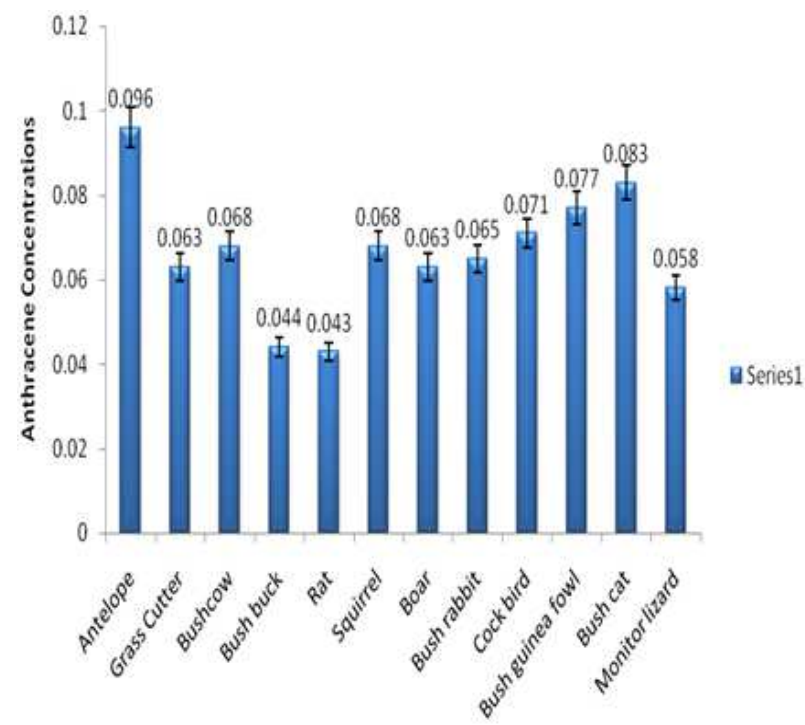

Figure 6. Anthracene concentrations for the various bush meat samples

Figure 8 show that samples of smoked bush meat also contained Fluoranthene concentrations. On the basis of obtained results it was found that smoked Antelope again contained Fluoranthene in concentrations substantially higher $(0.521 \mathrm{ppm})$ in comparison with the other 11 smoked bush meat samples.

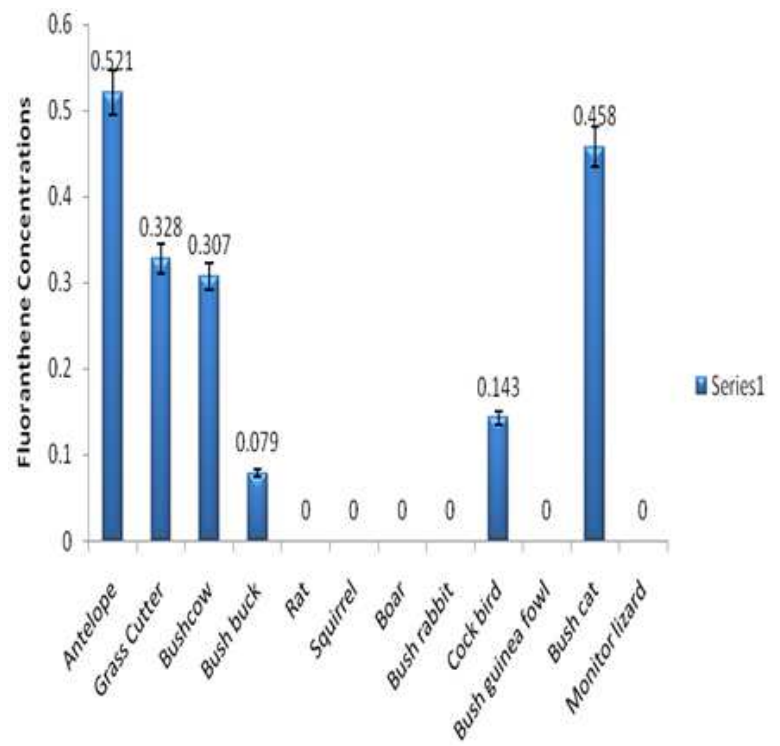

Figure 7. Flouranthene concentrations for the various bushmeat samples

Figure 9 show that samples of smoked bush meat also contained Pyrene concentrations. On the basis of obtained results it was found that smoked Cock bird contained Pyrene in concentrations substantially higher $(0.439 \mathrm{ppm})$ in comparison with the other 11 smoked bush meat samples. Smoked Antelope, Grass cutter, Bushcow, Rat, Squirrel, Boar, Bush cat, and Monitor Lizard did not contain Pyrene.

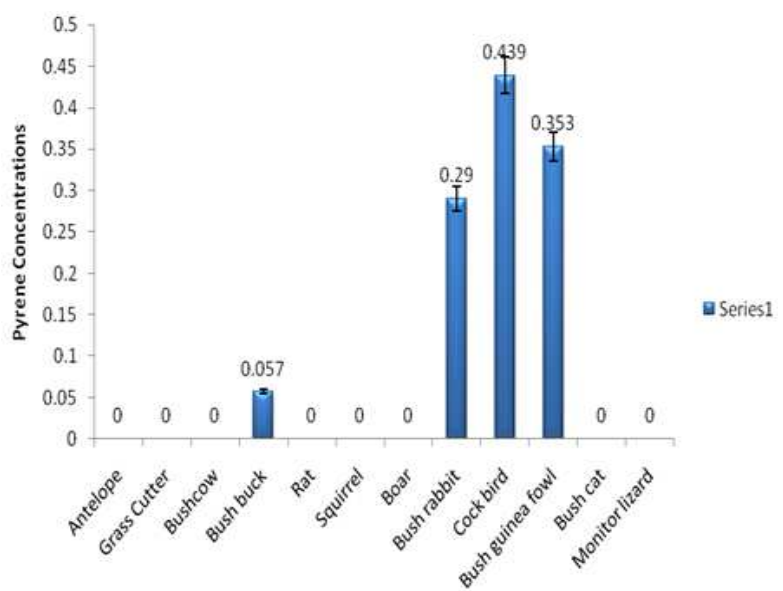

Figure 8. Pyrene concentrations for the various bushmeat samples

\subsection{Determinants of PAHs}

We observe from Table 2 that the between groups mean square (2.263) is many times larger than the within groups or error mean square (1.978). This indicates that it is unlikely that the means for the various PAHs from the different substances/methods used in singeing off the hair of animals in flames are equal. More formally, at $\alpha=0.05$, we find the significant probability or $\mathrm{p}$-value is 0.000 . Because the p-value $=0.000<0.05$, we conclude that the means for the various PAHs from the four different substances/methods differ significantly.

Table 1. Analysis of Variance for the various substances/methods

\begin{tabular}{cccccc}
\hline \multicolumn{5}{c}{ Concentrations } \\
\hline Source & $\begin{array}{c}\text { Sum of } \\
\text { Squares }\end{array}$ & df & Mean Square & F & Sig. \\
Between & 2.263 & 3 & .754 & 39.661 & .000 \\
Groups & 1.978 & 104 & .019 & & \\
Within Groups & 4.240 & 107 & & & \\
Total & & & & & \\
\hline
\end{tabular}

We observe from Table 3 that bushmeat smoked with Gas recorded $\mathrm{PAH}$ values that are significantly smaller (Mean $=0.0309 \mathrm{ppm}$ ) than bushmeat smoked with wood mixed with spent oil, plastics mixed with refuse, and discarded car tyres. Bushmeat smoked with discarded car tyres recorded the highest PAH concentrations (Mean=0.4336ppm).

Table 2. Total PAH concentrations expresses in ppm

\begin{tabular}{lll}
\hline Substance/Method & N & Mean \pm SE \\
\hline Gas & 27 & $0.0309 \pm 0.0065^{\mathrm{a}}$ \\
Wood mixed with spent oil & 27 & $0.17296 \pm 0.0305^{\mathrm{b}}$ \\
Plastics mixed with refuse & 27 & $0.1898 \pm 0.0251^{\mathrm{b}}$ \\
Discarded car tyres & 27 & $0.4336 \pm 0.0349^{\mathrm{c}}$ \\
\hline
\end{tabular}

a,b,c: Means that do not share a common alphabet are significantly different $(\mathrm{P}<0.05)$ 


\section{Conclusion}

The implications from this study are quite clear. First of all, we investigated to assess the levels of PAH in smoked bushmeat. The results reveal that in terms of Naphthalene, 2-Methylnaphthalene, Acenaphthylene, Aacenaphthene, Phenanthrene, Antracene, and Fluoranthene, smoked antelope had the highest levels of concentrations whiles smoked rat recorded the lowest concentrations. For Fluorene, smoked Bush cat recorded the highest level of concentration whereas smoked rat recorded the lowest level of concentration. Finally for Pyrene, smoked Cock bird had the highest level of concentration whiles smoked rat again recorded the lowest level of concentration.

Also, we investigated to determine among the substances/methods used in singeing off the hair of animals in flames, the substance/method that produces the least PAHs. The results reveal that, when bushmeat is smoked using Gas it produces smaller PAH values compared with bushmeat smoked using wood mixed with spent oil, plastics mixed with refuse, and discarded car tyres.

\section{References}

[1] I.S. Viksna, A. Morozovs, V. Bartkevics, and A. Kukare, "Levels of Benzo(a)pyrene (BaP) in Fish, Smoked According to Different Procedures," LLU Raksti, Vol 21(315), 2008, pp. 24-29

[2] L. Chen, P.D. Devanesan, S. Higginbotham, F. Ariese, R. Jankowiak, G.J. Small, E.G. Rogan and E.L. Cavalieri, "Expanded Analysis of Benzo[a]pyrene-DNA Adducts Formed in Vitro and in Mouse Skin: Their Significance in Tumor Initiation," Chemical Research in Toxicology, Vol 9, 1996, pp. 897-903

[3] P. Simko, "Determination of Polycyclic Aromatic
Hydrocarbons in Smoked Meat Products and Smoked Flavouring Additives," J of Chromatographica, Vol 770, 2002, pp. 3-18

[4] S. Wretling, A. Eriksson, G.A. Eskhult and B. Larson, "Polycyclic Aromatic Hydrocarbons in Swedish Smoked Meats and Fish," J of Food Composition and Analysis, Vol 23(1), 2010, pp.264-272

[5] C. Anyakora, M. Arbabi, and H. Coker, "A Screen for Benzo(a)pyrene in Fish Samples from Crude Oil Polluted Environments," Am. J. Environ. Sci. Vol 4, 2008, pp. $145-150$

[6] S. King, J.S. Meyer, and A.R.J. Andrews, "Screening Method for Polycyclic Aromatic Hydrocarbons in Soil Using Hollow Fibre Membrane Solvent Microextraction," J. Chromatogr, Vol 982, 2002, pp. 201-208

[7] WHO, "Polycyclic Aromatic Hydrocarbons. In Air Quality Guidelines (2 ed.)," Copenhagen: World Health Organization, 2000

[8] C. Guy, D. Yves, A. Farida, A. Benoit, B. Gilles, B. Helene, C. Jean-Pierre, D. Fariba, G. Camille, G. Christelle, G. Daniel, I. Nathalie, M. Olivier, N. Guy, N. Lilliane, P. Patrick, S. Philippe, and V. Aurelie, "Influence of Oil Exposure on the Physiology and Ecology of the Common Sole Solea Solea: Experimental and Field Approaches," Aquatic Living Resources, Vol 17, 2004, pp. 335-351

[9] P. Simko, "Factors Affecting Elimination of Polycyclic Aromatic Hydrocarbons from Smoked Meat Foods and Liquid Smoke Flavourings,” Mol. Nutr. Food Res., Vol 49, 2005, pp.637-647

[10] M.D. Guillen, P. Sopelana, and M.A. Partearroyo, "Food as a Source of Polycyclic Aromatic Carcinogens," Rev. Environ. Health, Vol 12, 1997, pp. 133-146

[11] B.H. Chen, and Y.S. Lin, "Formation of Polycyclic Aromatic Hydrocarbons during Processing of Duck Meat. J. Agric. Food Chem., Vol 45, 1997, pp.1394-1403 